\title{
Old cortex, new contexts: re-purposing spatial perception for social cognition
}

\section{Carolyn Parkinson* and Thalia Wheatley}

Department of Psychological and Brain Sciences, Dartmouth College, Hanover, NH, USA

\section{Edited by: \\ Antonia Hamilton, University of \\ Nottingham, UK}

Reviewed by:

Ivan Toni, Radboud University,

Netherlands

Anna M. Borghi, Institute of Cognitive Sciences and Technologies, University of Bologna, Rome, Italy

\section{${ }^{*}$ Correspondence:}

Carolyn Parkinson, Department of Psychological and Brain Sciences, Dartmouth College, 6207 Moore Hall, Hanover, NH 03755, USA e-mail: carolyn.parkinson@gmail.com
Much of everyday mental life involves information that we cannot currently perceive directly, from contemplating the strengths of friendships to reasoning about the contents of other minds. Despite their primacy to everyday human functioning, and in particular, to human sociality, the mechanisms that support abstract thought are poorly understood. An explanatory framework that has gained traction recently in cognitive neuroscience is exaptation, or the re-purposing of evolutionarily old circuitry to carry out new functions. We argue for the utility of applying this concept to social cognition. Convergent behavioral and neuroscientific evidence suggests that humans co-opt mechanisms originally devoted to spatial perception for more abstract domains of cognition (e.g., temporal reasoning). Preliminary evidence suggests that some aspects of social cognition also involve the exaptation of substrates originally evolved for processing physical space. We discuss the potential for future work to test more directly if cortical substrates for spatial processing were exapted for social cognition, and in so doing, to improve our understanding of how humans evolved mechanisms for navigating an exceptionally complex social world.

Keywords: exaptation, neural reuse, social neuroscience, metaphor, spatial cognition, perspective taking, social distance, posterior parietal cortex

\section{EXAPTATION AND HUMAN COGNITION}

Our thoughts often include information outside of the current sensory environment, from imagined futures to the contents of other minds. However, the mechanisms supporting abstract cognition remain poorly understood. An explanatory framework that has gained traction recently (Gallese and Lakoff, 2005; Dehaene and Cohen, 2007; Anderson, 2010) involves exaptation: co-opting existing morphological features for novel functions (Gould and Vrba, 1982). New cognitive capacities may have emerged over the course of evolution when brain regions originally devoted to specific functions were repurposed and recombined in novel ways to process additional kinds of information (Anderson, 2010). Analogous cortical recycling processes may occur during development whereby cultural inventions co-opt circuitry evolved for older aspects of cognition (Dehaene and Cohen, 2007). Exaptation and cortical recycling provide plausible neural bases for proposals that representational resources originally devoted to space were co-opted to process more abstract information (e.g., Boroditsky, 2011).

If our ability to reason about abstract concepts resulted from evolutionary "tinkering" (Jacob, 1977) with neural mechanisms originally developed for operating on physical space, then demanding that these mechanisms handle conflicting inputs pertaining to their new and old functions simultaneously should create response conflict. Further, evidence from clinical and neuroimaging studies should suggest shared substrates for these functions. Both kinds of evidence are accumulating with respect to several domains of abstract cognition, most widely in studies relating temporal and numerical processing to spatial cognition (Hubbard et al., 2005; Bonato et al., 2012). Here, we highlight the potential for our understanding of the mechanisms underlying abstract social cognition to benefit from a similar approach, and review evidence that these mechanisms may be best understood in terms of the kinds of computations (e.g., distance judgments, perspective taking), rather than the domains of knowledge, that they involve.

\section{SOCIALITY AND HUMAN BRAIN EVOLUTION}

Humans come into the world seemingly hardwired to detect and connect with other minds (Wheatley et al., 2012), and maintaining this predisposition is closely tied to healthy development (Pavlova, 2012). Effectively perceiving and interpreting social cues is particularly crucial for humans, who must navigate an exceptionally flexible system of relationships with conspecifics (Fiske, 1991). The ability to meet the intensive computational demands of humans' complex social environment (e.g., forging alliances, sharing intentions, tactical deception; Harcourt, 1988, 1989; Tomasello et al., 2005 ) is thought to have been a driving force for cortical expansion during evolution (Dunbar, 1998). Consistent with this hypothesis, feats of social cognition presumed to be uniquely human, such as sharing intentions (Tomasello et al., 2005) and representing others' beliefs (representational theory of mind, RTOM; Call and Tomasello, 2008) involve cortical areas that underwent the most evolutionary expansion (e.g., lateral posterior parietal cortex, PPC; Van Essen et al., 2001; particularly the temporoparietal junction, TPJ; Saxe, 2006; Redcay et al., 2010). These aspects of social cognition (e.g., RTOM) tend to involve information that cannot be perceived directly (e.g., false beliefs), and are functionally (Gobbini et al., 2007) and structurally (Parkinson and Wheatley, 2012) dissociable from older social processes (e.g., motor resonance), suggesting they either involve entirely new structures or structures previously devoted to non-social functions. Gould and Vrba 
(1982) suggested that exaptation of complex traits would likely be followed by secondary adaptations to further support new functions. Consistent with PPC circuitry evolved for dealing with space having been exapted, then expanded, to support abstract social cognition, the PPC has an evolutionarily old role in spatial perception (it encodes space in our distant relatives, e.g., rats; Nitz, 2006), processes both social and spatial information in humans and other primates (Yamazaki et al., 2009), and has expanded (Van Essen et al., 2001) and formed new connections (Mantini et al., 2013) in humans as it came to support evermore abstract aspects of social cognition. Recent computational modeling experiments support the notion that human brain expansion was driven by the cognitive demands of human sociality (Dávid-Barrett and Dunbar, 2013). Importantly, large brain size has a great metabolic cost; the human brain accounts for $2 \%$ of body mass but requires $20 \%$ of the energy that we consume (Clark and Sokoloff, 1999). In order to outweigh the considerable metabolic cost of the larger brain that they require, the cognitive mechanisms supporting human sociality must have conferred substantial adaptive benefits.

However, compared to other domains of abstract cognition (e.g., mathematics; Hubbard et al., 2005), little is known about how social forms of abstract cognition (e.g., representing beliefs or one's place in a social network) relate to evolutionarily older aspects of cognition. This may be due to several factors. First, compared to cognitive neuroscience, social cognitive neuroscience is a young field (Ochsner, 2007); many aspects of social cognition have simply been studied less extensively than other aspects of cognition. Second, early social cognitive neuroscience research often assumed a modular view of the brain (Bergeron, 2007), and involved searching for encapsulated brain areas devoted to processing particular contents (Kihlstrom, 2010). If one understands an aspect of cognition to be supported by a domain-specific module, attempting to relate that aspect of cognition to other mental phenomena may not be considered a particularly worthwhile endeavor. More recently, brain areas (e.g., TPJ; fusiform face area) previously implicated in various facets of social information processing (e.g., RTOM; face perception) have been found to perform similar operations (e.g., reorienting attention, Mitchell, 2008; visual object encoding, Hanson et al., 2004) on diverse contents. Consistent with the suggestion that social cognition and physical perception involve common computations (Zaki, 2013), the functional significance of brain areas involved in social cognition may often be best characterized in terms of the operations they perform across multiple domains of information.

\section{LINGUISTIC MAPPINGS BETWEEN ABSTRACT COGNITION AND SPATIAL PERCEPTION}

One window into the cognitive operations supporting abstract thought is the language we use to describe them (Lakoff and Johnson, 1980). The spatialization of form hypothesis (Lakoff, 1987) specifically highlights the widespread use of spatial words (e.g., "outside," "far") to describe conceptual relations, suggesting that spatial schemata structure mental representations. Abstract relations may be represented in terms of space because unlike spatial relationships, they must be imagined rather than observed (Evans, 2006). We can observe two people sitting close together, gaze direction, or moving a vehicle forward, but can only imagine the closeness of a friendship, a belief, or moving a meeting forward (Casasanto et al., 2010). In this view, phrases like "close friendship" or "far from the truth" are not mere figures of speech, but rather, figures of thought that reveal the structure of mental representations (Lakoff, 1986). The extent to which representational overlap between space and abstract domains results from exaptation during evolution, metaphoric structuring acquired during development, or some combination of these processes, remains an open question. With respect to social processing, the recruitment of brain areas involved in reorienting visual attention (TPJ) while congenitally blind individuals perform RTOM tasks (Bedny et al., 2009) suggests that functional overlap between social and visuospatial processes may be an innately predisposed result of evolutionary exaptation that is now reflected in linguistic metaphors for mentalizing (e.g., "Try to see things from my point of view").

The domain of abstract cognition that has been studied most extensively in terms its relation to space is time. Cross-linguistic studies indicate that people around the world use spatial language to describe time (Boroditsky, 2011); the intuition to represent time analogously to space may be evolutionarily predisposed. Do all languages employ spatial language to describe social relationships (e.g., "close friend") and RTOM? Are mappings consistent across languages? Some cross-linguistic variability exists in spatiotemporal metaphors, but certain mappings (future $=$ forward) are nearly ubiquitous, likely due to shared aspects of human physiology and experience. Similarly, some English spatial metaphors for social relationships (familiarity $=$ closeness) may stem from the tendency to give personal space to others based on the "closeness" of relationships (Hayduk, 1983). To our knowledge, metaphoric mappings between spatial and social relationships or between visuospatial and social perspective taking have not been subjected to exhaustive cross-linguistic analysis. Thus, whether or not humans around the world use space to structure mental representations of the magnitude and traversal of social distances remains an open question.

\section{BEHAVIORAL EVIDENCE FOR MAPPINGS BETWEEN ABSTRACT COGNITION AND SPATIAL PERCEPTION}

Behavioral mappings between space and abstract cognition have been most extensively studied with respect to time and number. Number and space are associated implicitly; according to the spatial numerical association of response codes (SNARC) effect, people are faster to respond regarding small numbers on the left side of space, and large numbers on the right side of space, even for tasks unrelated to magnitude (Dehaene et al., 1993). Similar associations have been documented between number and elevation (Pecher and Boot, 2011; Lugli et al., 2013). Representational overlap between space and number appears to comprise a universal human intuition (Dehaene et al., 2008), and can be documented outside of the laboratory. When thinking about numbers, more than $10 \%$ of individuals report automatically accessing mental "number forms" consisting of spatial layouts (Seron et al., 1992). It has even been suggested that on the scale of motoric action, time, space, and quantity are processed by an analog magnitude system (Walsh, 2003), which was co-opted to process discrete number (Bueti and Walsh, 2009). 
Stimulus-response compatibility codes also exist for time (Ishihara et al., 2008; Sell and Kaschak, 2011). Additionally, people tend to spontaneously sway forward while imagining the future and backward while imagining the past, suggesting that representations of movement through space are automatically activated during imagined movement through time (Miles et al., 2010). Monkeys (Merritt et al., 2010) and infants without exposure to relevant linguistic or sensorimotor mappings (Srinivasan and Carey, 2010) exhibit representational overlap between spatial extent and temporal duration (but not all magnitudes), suggesting that spatiotemporal mappings originate from common processing mechanisms, independently of sensorimotor grounding or linguistic correspondences.

Social and spatial information are also behaviorally associated. Visual perspective taking and mentalizing abilities are positively correlated (Flavell et al., 1986; Hamilton et al., 2009). People readily convert judgments of social compatibility into physical distances (Yamakawa et al., 2009). Words characterizing close social distances (e.g., "us," "friend") are associated with close locations, and words characterizing remote social distances (e.g., "them," "enemy") are associated with far spatial locations (Bar-Anan et al., 2007). Additionally, consistent with the suggestion that out-group members are construed as being physically distant from oneself (except following threat, Xiao and Van Bavel, 2012), Jones et al. (1981) found that out-group members are rated as more homogenous (i.e., having a narrower range of personal characteristics) than in-group members. Similarly, powerful individuals, who see themselves as exceptionally distinctive, construe others as exceptionally distant and homogenous (Fiske, 1993; Lee and Tiedens, 2001). It may be parsimonious to represent social and spatial distances analogously: Construal level theory of psychological distance (Liberman and Trope, 2008) posits that spatial, temporal and social egocentric distance share a common psychological meaning - distance from the self in the here and now.

Although extant research highlights a possible relationship between mental representations of social and spatial information, more research is needed to explore this possibility, and address several remaining questions, such as: is there a hierarchy of egocentric psychological distance domains, in which some are more primary than others? Do we spontaneously access representations of moving through space when traversing "social" distances or perspective taking, like during mental time travel? Are spatial representations activated explicitly when thinking about social relationships in everyday life, as they are for many individuals when thinking about numbers? Exploring questions like these will lead to an improved understanding of the mechanisms involved in abstract social cognition.

\section{NEUROSCIENTIFIC EVIDENCE FOR MAPPINGS BETWEEN ABSTRACT COGNITION AND SPATIAL PERCEPTION}

If spatial processing were repurposed for abstract cognition, one would expect overlapping neural substrates. Past research suggests that PPC systems for sensorimotor control and cognition largely overlap (Creem-Regehr, 2009). As the PPC expanded in size over the course of human evolution (Van Essen et al., 2001), it appears to have expanded in function as well, leading to suggestions that mechanisms originally devoted to representing peripersonal space were repurposed to perform analogous operations on new contents. According to this theory, mechanisms previously dedicated to representing spatial information about the current sensory environment were first co-opted to represent simulations of peripersonal space in the past and future to support episodic memory and prospection, and later, to represent information in increasingly abstract frames of reference (Yamazaki et al., 2009). A growing body of neuroimaging and neuropsychological evidence suggests that representations of spatial and abstract information, including aspects of social cognition, are associated in the PPC.

Functional magnetic resonance imaging (fMRI) studies in humans implicate the PPC in representing perceptual, temporal, social and conceptual frames of reference (Yamazaki et al., 2009). Importantly, most of these results are based on overlapping activations from univariate contrasts, which could reflect shared neural codes or nearby but distinct codes for different kinds of information (Peelen and Downing, 2007). Multivariate pattern analysis (MVPA), which compares distributed patterns of activity between experimental conditions, rather than regionally smoothed and averaged responses, may better characterize brain regions' representational contents (Figure 1). The few studies that have used MVPA to compare spatial and abstract cognition in the PPC support the suggestion that representations of spatial information "scaffold" those of more abstract information. A pattern classifier trained only to distinguish PPC responses to leftward vs. rightward saccades can distinguish mental addition from subtraction (Knops et al., 2009). Additionally, position and valence words can be decoded by a classifier trained only on patterns of PPC activity corresponding to visual elevation (Quadflieg et al., 2011). Because MVPA can reveal information about underlying cognitive structures (Figure 1), this approach will be valuable in elucidating whether use of spatial language in describing abstract social concepts reflects true representational similarities or linguistic bottlenecks that push people to use metaphors in the absence of adequate domain-specific terminology (such bottlenecks have been demonstrated in olfaction; Yeshurun and Sobel, 2010).

Further research is needed to characterize the relationship between the PPC's involvement in social and spatial cognition. For instance, the TPJ is recruited both when subjects reason about others' false beliefs and positions in space (Abraham et al., 2008), suggesting that this region may perform similar computations on visuospatial and social contents. MVPA could be used to more directly test this possibility. Similarly, judgments about hierarchy and social distance recruit areas of the PPC involved in self-referential physical distance processing (Chiao et al., 2009; Yamakawa et al., 2009). Does this brain region represent "high" social status and "close" social distances analogously to how it represents "high" spatial location and "close" spatial distances? Again, characterizing the representational structure of the PPC with MVPA could elucidate this question (Figure 1).

Neuropsychological data also suggests a close relationship between representations of spatial and abstract information in the PPC. Patients with left hemineglect following right PPC damage often also neglect the "left" side of the mental number line (Zorzi et al., 2002), whereas PPC lesion patients without neglect show no numerical deficits (Vuilleumier et al., 2004). Remarkably, 


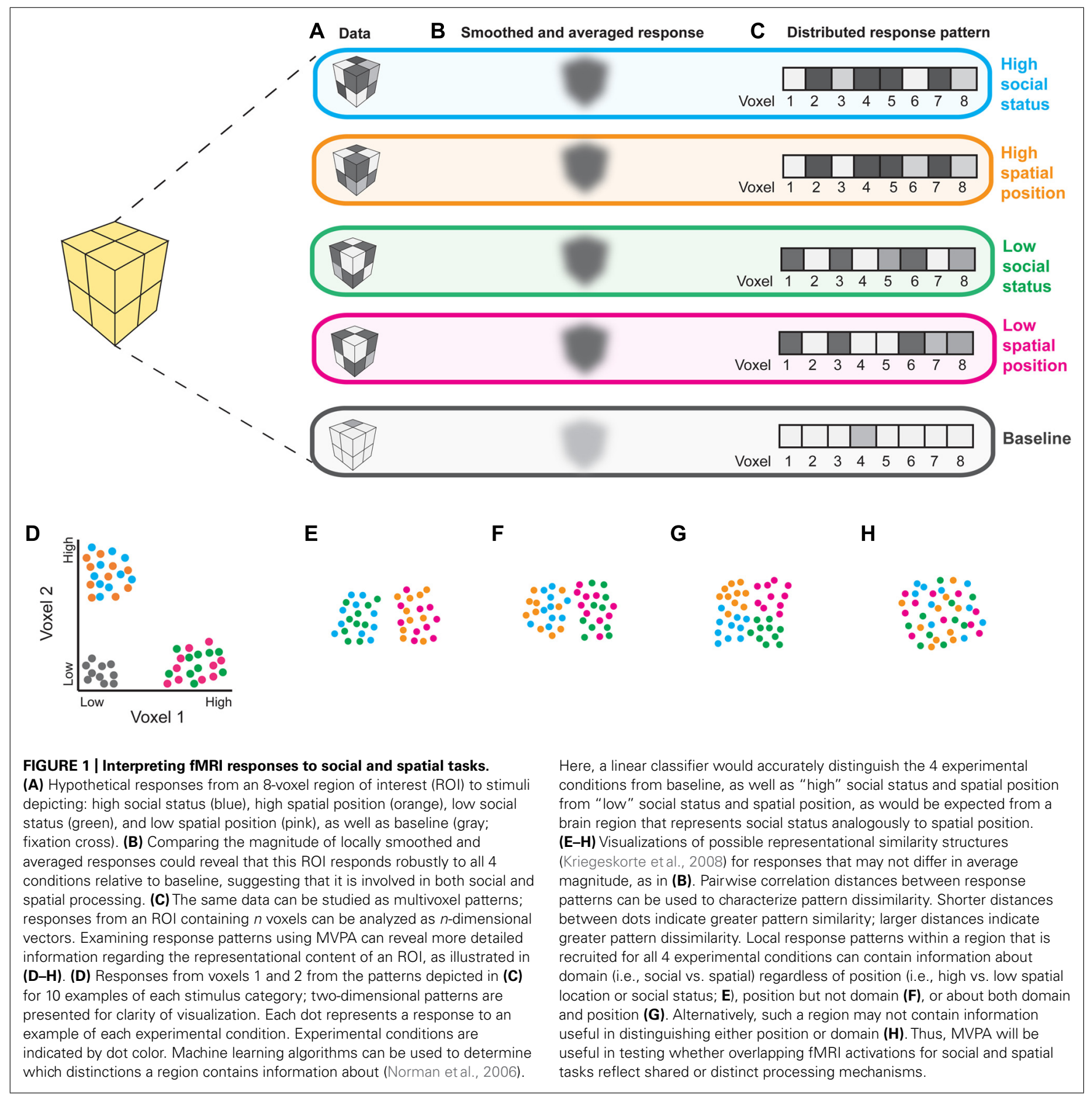

normal numerical processing is restored in neglect patients following interventions utilizing adaptation to leftward-shifting prism glasses that restore visual attention to the previously neglected side of space (Rossetti etal., 2004). Patients with hemispatial neglect exhibit analogous distortions of temporal processing, systematically overestimating temporal durations (Basso et al., 1996; Calabria et al., 2011). Spatiotemporal mappings appear to be supported by the PPC in healthy individuals, as they are diminished following transcranial magnetic stimulation to this region (Oliveri et al., 2009). Neuropsychological studies relating spatial and abstract cognition have focused primarily on non-social domains

of abstract cognition (e.g., time, number) and space. However, Samson et al. (2004) reported impaired mentalizing in patients with focal lesions to the inferior PPC. To our knowledge, no studies have tested if PPC damage is associated with abnormal representations of one's social network.

One limitation of neuroscientific evidence relating space and other domains of cognition is that data are available only from individuals in industrialized societies, and many of the corresponding behavioral phenomena are malleable to cultural learning (Dehaene etal., 1993). Although the tendency to map various domains of knowledge onto spatial representations appears to 
comprise a universal intuition (Dehaene et al., 2008; Parkinson et al., 2012), the nature of these mappings is often subject to cultural variation (Hung et al., 2008; Boroditsky and Gaby, 2010). Even two weeks of tool use engenders white and gray matter changes in the macaque PPC (Hubbard et al., 2005; Iriki, 2005). Lifelong immersion in cultures emphasizing metaphors and analogical reasoning no doubt impacts neural representations. Although the work summarized here is drawn from studies conducted in several countries, more cross-cultural work, especially that involving direct cross-cultural comparisons, is required to better understand how representational overlap between spatial and social cognition arises in the brain.

\section{COMPARING SPATIAL REPRESENTATIONS BETWEEN DOMAINS OF KNOWLEDGE}

Importantly, although multiple domains of abstract cognition appear to co-opt mechanisms for spatial processing, different exaptations could have arisen separately, and may operate differently. There is a paucity of research investigating how different domains of knowledge that use space as a "reference domain" relate to one another. Different processes may have independently come to co-opt circuitry originally for spatial computations because such an arrangement was efficient and likely given pre-existing anatomical and functional constraints (Cantlon etal., 2009). Consistent with this suggestion,

\section{REFERENCES}

Abraham, A., Werning, M., Rakoczy, H., von Cramon, D. Y., and Schubotz, R. I. (2008). Minds, persons, and space: an fMRI investigation into the relational complexity of higher-order intentionality. Conscious. Cogn. 17, 438-450. doi: 10.1016/j.concog.2008. 03.011

Anderson, M. L. (2010). Neural reuse: a fundamental organizational principle of the brain. Behav. Brain Sci. 33, 245-266. doi: 10.1017/S0140525X10000853

Bar-Anan, Y., Liberman, N., Trope, Y., and Algom, D. (2007). Automatic processing of psychological distance: evidence from a Stroop task. J. Exp. Psychol. Gen. 136, 610-622. doi: 10.1037/0096-3445.136.4.610

Basso, G., Nichelli, P., Frassinetti, F., and di Pellegrino, G. (1996). Time perception in a neglected space. Neuroreport 7, 2111-2114. doi: 10.1097/00001756-199609020-00009

Bedny, M., Pascual-Leone, A., and Saxe, R. R. (2009). Growing up blind does not change the neural bases of theory of mind. Proc. Natl. Acad. Sci. U.S.A. 106, 11312-11317. doi: 10.1073/pnas.0900010106

Beecham, R., Reeve, R. A., and Wilson, S. J. (2009). Spatial representations are specific to different domains of knowledge. PLOS ONE 4:e5543. doi: 10.1371/journal.pone. 0005543
Bergeron, V. (2007). Anatomical and functional modularity in cognitive science: shifting the focus. Philos. Psychol. 20, 175-195. doi: 10.1080/09515080701197155

Bonato, M., Zorzi, M., and Umiltà, C. (2012). When time is space: evidence for a mental time line. Neurosci. Biobehav. Rev. 36, 22572273. doi: 10.1016/j.neubiorev.2012. 08.007

Boroditsky, L. (2011). "How languages construct time," in Space, Time and Number in the Brain, eds S. Dehaene and E. Brannon (London: Elsevier), 333-341.

Boroditsky, L., and Gaby, A. (2010). Remembrances of times East: absolute spatial representations of time in an Australian Aboriginal community. Psychol. Sci. 21, 1635-1639. doi: 10.1177/0956797610386621

Bueti, D., and Walsh, V. (2009). The parietal cortex and the representation of time, space, number, and other magnitudes. Philos. Trans. R. Soc. B Biol. Sci. 364, 1831-1840. doi: 10.1098/rstb.2009.0028

Calabria, M., Jacquin-Courtois, S., Miozzo, A., Rossetti, Y., Padovani, A., Cotelli, M., et al. (2011). Time perception in spatial neglect: a distorted representation. Neuropsychola0021304

Call, J., and Tomasello, M. (2008) Does the chimpanzee have a theory ogy 25, 193-200. doi: 10.1037/

a recent study comparing spatial representations of number and pitch within individuals suggests that spatial representations are idiosyncratic to specific domains of knowledge (Beecham et al., 2009). Thus, although past work relating spatial cognition to non-social aspects of abstract cognition will be informative for future studies aimed at characterizing the relationship between spatial perception and social cognition, this will not be a trivial endeavor.

\section{CONCLUSION}

Convergent evidence from behavior, neuropsychology, and neuroimaging suggest that humans use knowledge about space to scaffold mental representations of abstract information. Whereas most investigations have focused on non-social domains of abstract cognition, less work has explored the relationship between abstract aspects of social cognition (e.g., social distance evaluation, mentalizing) and spatial perception. Given the substantial progress that has stemmed from using this approach to characterize the mechanisms that support non-social domains of abstract cognition, we predict that relating abstract social cognition to spatial perception will be similarly fruitful. Further, given the centrality of sociality to human health and brain evolution (Dunbar, 1998), better understanding the mechanisms involved in social cognition is essential to understanding the human brain more generally.

of mind? 30 years later. Trends Cogn. Sci. 12, 187-192. doi: 10.1016/j.tics.2008.02.010

Cantlon, J. F., Platt, M. L., and Brannon, E. M. (2009). Beyond the number domain. Trends Cogn. Sci. 13, 83-91. doi: 10.1016/j.tics.2008.11.007

Casasanto, D., Fotakopoulou, O., and Boroditsky, L. (2010). Space and time in the child's mind: evidence for a cross-dimensional asymmetry. $\operatorname{Cog} n$. Sci. 34, 387-405. doi: 10.1111/j.15516709.2010.01094.x

Chiao, J., Harada, T., Oby, E., Li, Z., and Parrish, T. (2009). Neural representations of social status hierarchy in human inferior parietal cortex. Neuropsychologia $47,354-363$. doi: $10.1016 / \mathrm{j}$. neuropsychologia.2008.09.023

Clark, D. D., and Sokoloff, L. (1999). "Circulation and energy metabolism of the brain," in Basic Neurochemistry: Molecular, Cellular and Medical Aspects, eds G. J. Siegel, B. W. Agranoff, R. W. Albers, S. K. Fisher, and M. D. Uhler (Philadelphia, PA: Lippincott), 637-670.

Creem-Regehr, S. H. (2009). Sensorymotor and cognitive functions of the human posterior parietal cortex involved in manual actions. Neurobiol. Learn. Mem. 91, 166-171. doi: 10.1016/j.nlm.2008. 10.004

Dávid-Barrett, T., and Dunbar, R. I. M. (2013). Processing power limits social group size: computational evidence for the cognitive costs of sociality. Proc. Biol. Sci. 280, 20131151. doi: 10.1098/rspb.2013.1151

Dehaene, S., Bossini, S., and Giraux, P. (1993). The mental representation of parity and number magnitude. J. Exp. Psychol. Gen. 122, 371-396. doi: 10.1037/00963445.122.3.371

Dehaene, S., and Cohen, L. (2007). Cultural recycling of cortical maps. Neuron 56, 384-398. doi: 10.1016/j.neuron.2007.10.004

Dehaene, S., Izard, V., Spelke, E., and Pica, P. (2008). Log or linear? Distinct intuitions of the number scale in Western and Amazonian Indigene cultures. Science 320, 1217-1220. doi: 10.1126/science. 1156540

Dunbar, R. I. M. (1998). The social brain hypothesis. Evolut. Anthropol. 6, 178-190. doi: 10.1002/(SICI) 15206505(1998)6:5<178::AID-EVAN5>3. $0 . \mathrm{CO} ; 2-8$

Evans, V. (2006). The Structure of Time: Language, Meaning and Temporal Cognition. Amsterdam: Braziller.

Fiske, A. P. (1991). Structures of Social Life: The Four Elementary Forms of Human Relations. New York: Free Press.

Fiske, S. T. (1993). Controlling other people: the impact of power on stereotyping. Am. Psychol. 48, 621-628. doi: 10.1037/0003066X.48.6.621 
Flavell, J. H., Green, F. L., and Flavell, E. R. (1986). Development of knowledge about the appearancereality distinction. Monogr. Soc. Res. Child Dev. 51, 1-87. doi: 10.2307/ 1165866

Gallese, V., and Lakoff, G. (2005) The brain's concepts: the role of the sensory-motor system in conceptual knowledge. Cogn. Neuropsychol. 22, 455-479. doi: 10.1080/ 02643290442000310

Gobbini, M. I., Koralek, A. C., Bryan, R. E., Montgomery, K. J., and Haxby, J. V. (2007). Two takes on the social brain: a comparison of theory of mind tasks. J. Cogn. Neurosci. 19, 1803-1814. doi: 10.1162/jocn.2007.19.11.1803

Gould, S., and Vrba, E. (1982). Exaptation - a missing term in the science of form. Paleobiology 8, 4-15.

Hamilton, A. F., Brindley, R., and Frith, U. (2009). Visual perspective taking impairment in children with autistic spectrum disorder. Cognition 113, 37-44. doi: 10.1016/j.cognition.2009.07.007

Hanson, S. J., Matsuka, T., and Haxby, J. V. (2004). Combinatorial codes in ventral temporal lobe for object recognition: Haxby (2001) revisited: is there a "face" area? Neuroimage 23, 156-166. doi: 10.1016/j.neuroimage.2004.05.020

Harcourt, A. H. (1988). "Alliances in contests and social intelligence," in Machiavellian Intelligence, eds R. Byrne and A. Whiten (Oxford: Oxford University Press), 142-152.

Harcourt, A. H. (1989). "Sociality and competition in primates and nonprimates," in Comparative Socioecology, eds V. Standen and R. Foley (Oxford: Blackwell Scientific), 223242.

Hayduk, L. A. (1983). Personal space: where we now stand. Psychol. Bull. 94, 293-335. doi: 10.1037/00332909.94.2.293

Hubbard, E. M., Piazza, M., Pinel, P., and Dehaene, S. (2005). Interactions between number and space in parietal cortex. Nat. Rev. Neurosci. 6, 435-448. doi: 10.1038/nrn1684

Hung, Y.-H., Hung, D. L., Tzeng, O. J. L., and Wu, D. H. (2008). Flexible spatial mapping of different notations of numbers in Chinese readers. Cognition 106, 14411450. doi: 10.1016/j.cognition.2007. 04.017

Iriki, A. (2005). "A prototype of homo faber: a silent precursor of human intelligence in the tool-using monkey brain," in From Monkey Brain to Human Brain: A Fyssen Foundation Symposium, eds S. Dehaene, J. R. Duhamel, M. D. Hauser, and G.
Rizzolatti (Cambridge: MIT Press), 253-272.

Ishihara, M., Keller, P. E., Rossetti, Y., and Prinz, W. (2008) Horizontal spatial representations of time: evidence for the STEARC effect. Cortex 44, 454-461. doi: 10.1016/j.cortex.2007.08.010

Jacob, F. (1977). Evolution and tinkering. Science 196, 1161-1166. doi: 10.1126/science.860134

Jones, E. E., Wood, G. C., and Quattrone, G. A. (1981). Perceived variability of personal characteristics in in-groups and out-groups: the role of knowledge and evaluation. Pers. Soc. Psychol. Bull. 7, 523-528, doi: 10.1177/014616728173024

Kihlstrom, J. F. (2010). Social neuroscience: the footprints of Phineas Gage. Soc. Cogn. 28, 757-783. doi: 10.1521/soco.2010.28.6.757

Knops, A., Thirion, B., Hubbard, E. M., Michel, V., and Dehaene, S. (2009). Recruitment of an area involved in eye movements during mental arithmetic. Science 324, 1583-1585. doi: 10.1126/science.1171599

Kriegeskorte, N., Mur, M., and Bandettini, P. (2008). Representational similarity analysis: connecting the branches of systems neuroscience. Front. Syst. Neurosci. 2:4. doi: 10.3389/neuro.06.004 2008

Lakoff, G. (1986). A figure of thought Metaphor Symb. 1, 215-225. doi: $10.1207 / \mathrm{s} 15327868 \mathrm{~ms} 0103 \_4$

Lakoff, G. (1987). Women, Fire, and Dangerous Things: What Categories Reveal about the Mind. Chicago: Chicago Press.

Lakoff, G., and Johnson, M. (1980). Metaphors We Live By. Chicago: University of Chicago Press.

Lee, F., and Tiedens, L. Z. (2001) Is it lonely at the top? The independence and interdependence of power holders. Res. Org. Behav. 23, 43-91. doi: 10.1016/S0191-3085(01) 23003-2

Liberman, N., and Trope, Y. (2008). The psychology of transcending the here and now. Science 322, 1201-1205. doi: 10.1126/science.1161958

Lugli, L., Baroni, G., Anelli, F., Borghi, A. M., and Nicoletti, R. (2013). Counting is easier while experiencing a congruent motion. PLoS ONE 8:e64500. doi: 10.1371/journal.pone. 0064500

Mantini, D., Corbetta, M., Romani, G. L., Orban, G. A., and Vanduffel, W. (2013). Evolutionarily novel functional networks in the human brain? J. Neurosci. 33, 32593275. doi: 10.1523/JNEUROSCI. 4392-12.2013
Merritt, D. J., Casasanto, D., and Brannon, E. M. (2010). Do monkeys think in metaphors? Representations of space and time in monkeys and humans. Cognition 117, 191202. doi: 10.1016/j.cognition.2010. 08.011

Miles, L. K., Nind, L. K., and Macrae, C. N. (2010). Moving through time. Psychol. Sci. 21, 222-223. doi: $10.1177 / 0956797609359333$

Mitchell, J. P. (2008). Activity in right temporo-parietal junction is not selective for theory-of-mind. Cereb Cortex 18, 262-271. doi: 10.1093/cercor/bhm051

Nitz, D. A. (2006). Tracking route progression in the posterior parietal cortex. Neuron 49, 747-756. doi: 10.1016/j.neuron.2006.01.037

Norman, K. A., Polyn, S. M., Detre, G. J., and Haxby, J. V. (2006). Beyond mind-reading: multi-voxel pattern analysis of fMRI data. Trends Cogn. Neurosci. 10, 424-430. doi: 10.1016/j.tics.2006.07.005

Ochsner, K. N. (2007). "Social cognitive neuroscience: historical development, core principles, and future promise," in Social Psychology: A Handbook of Basic Principles, eds A. Kruglanksi and E. T. Hig gins (New York: Guillford Press), 38-66.

Oliveri, M., Koch, G., Salerno, S., Torriero, S., Gerfo Lo, E., and Caltagirone, C. (2009). Representation of time intervals in the right posterior parietal cortex: implications for a mental time line. NeuroImage 46, 1173-1179. doi: 10.1016/j.neuroimage.2009.03.042

Parkinson, C., Kohler, P., Sievers, B., and Wheatley, T. (2012). Associations between auditory pitch and visual elevation do not depend on language: evidence from a remote population. Perception 41, 854-861. doi: 10.1068/p7225

Parkinson, C., and Wheatley, T. (2012). Relating anatomical and social connectivity: white matter microstructure predicts emotional empathy. Cereb. Cortex doi: 10.1093/cercor/bhs347 [Epub ahead of print].

Pavlova, M. A. (2012). Biological motion processing as a hallmark of social cognition. Cereb. Cortex 22, 981-995. doi: 10.1093/cercor/ bhr156

Pecher, D., and Boot, I. (2011). Numbers in space: differences between concrete and abstract situations. Front. Psychol. 2:121. doi: 10.3389/fpsyg.2011.00121

Peelen, M., and Downing, P. (2007). Using multi-voxel pattern analysis of fMRI data to interpret overlapping functional activations. Trends Cogn. Sci. 11, 4-5. doi: 10.1016/j.tics.2006.10.009

Quadflieg, S., Etzel, J. A., Gazzola, V., Keysers, C., Schubert, T. W., Waiter, G. D., etal. (2011). Puddles, parties, and professors: linking word categorization to neural patterns of visuospatial coding. J. Cogn. Neurosci. 23, 2636-2649. doi: 10.1162/jocn.2011.21628

Redcay, E., Dodell-Feder, D., Pearrow, M. J., Mavros, P. L., Kleiner, M., Gabrieli, J. D., et al. (2010). Live face-to-face interaction during fMRI: a new tool for social cognitive neuroscience. Neuroimage 50, 16391647. doi: 10.1016/j.neuroimage. 2010.01.052

Rossetti, Y., Jacquin-Courtois, S., Rode, G., Ota, H., Michel, C., and Boisson, D. (2004). Does action make the link between number and space representation? Visuo-manual adaptation improves number bisection in unilateral neglect. Psychol. Sci. 15, 426430. doi: 10.1111/j.0956-7976.2004. 00696

Samson, D., Apperly, I. A., Chiavarino, C., and Humphreys, G. W. (2004). Left temporoparietal junction is necessary for representing someone else's belief. Nat. Neurosci. 7, 499-500. doi: 10.1038/ nn 1223

Saxe, R. (2006). Uniquely human social cognition. Curr. Opin. Neurobiol. 16, 235-239. doi: 10.1016/j.conb.2006. 03.001

Sell, A. J., and Kaschak, M. P. (2011). Processing time shifts affects the execution of motor responses. Brain Lang. 117, 39-44. doi: 10.1016/j.bandl.2010.07.003

Seron, X., Pesenti, M., Noël, M. P., Deloche, G., and Cornet, J. A. (1992). Images of numbers, or "When 98 is upper left and 6 sky blue". Cognition 44, 159-196. doi: 10.1016/00100277(92)90053-K

Srinivasan, M., and Carey, S. (2010). The long and the short of it: on the nature and origin of functional overlap between representations of space and time. Cognition 116, 217241. doi: 10.1016/j.cognition.2010. 05.005

Tomasello, M., Carpenter, M., Call, J., Behne, T., and Moll, $\mathrm{H}$. (2005). Understanding and sharing intentions: the origins of cultural cognition. Behav. Brain Sci. 28, 675-735. doi: 10.1017/S0140525X05 000129

Van Essen, D. C., Lewis, J. W., Drury, H. A., Hadjikhani, N., Tootell, R. B., Bakircioglu, M., et al. (2001). Mapping visual cortex in 
Parkinson and Wheatley

Spatial perception and social cognition

monkeys and humans using surfacebased atlases. Vise. Res. 41, 13591378. doa: 10.1016/S0042-6989(01) 00045-1

Vuilleumier, P., Ortigue, S., and Bugger, P. (2004). The number space and neglect. Cortex 40, 399410. doa: 10.1016/S0010-9452(08) 70134-5

Walsh, V. (2003). A theory of magnitude: common cortical metrics of time, space and quantity. Trends Conn. Sci. 7, 483-488. doe: 10.1016/j.tics.2003.09.002

Wheatley, T., Kans, O., Parkinson, C., and Looser, C. (2012). From mind perception to mental connection: synchrony as a mechnism for social understanding. Soc. Prs. Psychol. Compass 6, 589606. doa: 10.1111/j.1751-9004.2012. 00450.x
Xiao, Y. J., and Van Bevel, J. J. (2012). See your friends close and your enemies closer: social identity and identity threat shape the representation of physical distance. Prs. Soc. Psychol. Bull. 38, 959-972. do: 10.1177/0146167212 442228

Yamakawa, Y., Kenai, R., Matsumura, M., and Naito, E. (2009). Social distance evaluation in human parietal cortex. CLoS ONE 4:e4360. doa: 10.1371/journal.pone. 0004360

Yamazaki, Y., Hashimoto, T., and Iriki, A. (2009). The posterior parietal cortex and non-spatial cognition. F1000. Biol. Rep. 1, 74. do: 10.3410/ B1-74

Yeshurun, Y., and Sobel, N. (2010). An odor is not worth a thousand words: from multidimensional odors to unidimensional odor objects. Annu. Rev. Psychol. 61, 219-241. do: 10.1146/annurev.psych.60.110707. 163639

Raki, J. (2013). Cue integration: a common framework for social cognition and physical percepion. Perspect. Psychol. Sci. 8, 296-312. do: 10.1177/1745691613 475454

Zorzi, M., Priftis, K., and Umiltà, C. (2002). Brain damage: neglect disrupts the mental number line. Nature 417, 138-139. doa: 10.1038/ $417138 \mathrm{a}$

Conflict of Interest Statement: The authors declare that the research was conducted in the absence of any commercial or financial relationships that could be construed as a potential conflick of interest.
Received: 15 July 2013; accepted: 17 September 2013; published online: 08 October 2013.

Citation: Parkinson $C$ and Wheatley $T$ (2013) Old cortex, new contexts: re-purposing spatial perception for social cognition. Front. Hum. Neurosci. 7:645. do: 10.3389/fnhum.2013.00645 This article was submitted to the journal Frontiers in Human Neuroscience. Copyright (๑) 2013 Parkinson and Wheatley. This is an open-access article distribute under the terms of the Creative Commons Attribution License (CC BY). The use, distribution or reproduction in other forums is permitted, provided the original authors) or licenser are credted and that the original publication in this journal is cited, in accordance with accepted academic practice. No use, distribution or reproduction is permitted which does not comply with these terms.

Frontiers in Human Neuroscience

www.frontiersin.org

October 2013 | Volume 7 | Article 645 | 7 